\title{
Dependency Levels and Related Factors of Individuals Receiving Home Based Health Care in Turkey
}

\section{Ören MM* and Önal AE}

Department of Public Health, İstanbul University Faculty of Medicine, Turkey

*Corresponding author: Meryem Merve Ören, Department of Public Health, İstanbul University Faculty of Medicine, Turkey, Tel: +902124142000; Email: meryem.oren@istanbul.edu.tr

\section{Research Article}

Volume 4 Issue 2

Received Date: February 13, 2020

Published Date: March 03, 2020

DOI: $10.23880 /$ nhij- 16000218

\section{Abstract}

Background: The need for health services is increasing steadily and hospital resources to meet this need are quite limited. Patients who need home based health care (HBHC) constitute a significant part of this need. The aim of this study was to determine the dependence levels and related factors of HBHC patients in Istanbul.

Methods: Our descriptive study was carried out with 134 patients who were enrolled between January 1st and May 15th of 2016 due to the need for HBHC. Sociodemographic information, data on chronic diseases and related to the need for HBHC, were evaluated by means of the questionnaire, and dependence levels were evaluated with Barthel Index.

Results: The mean age was $77.5 \pm 14.7$ years. The group consisted of $61.2 \%$ women; $61.9 \%$ were single or in widowhood and $43.3 \%$ were illiterate. Some $86.6 \%$ of the patients who received HBHC services were looked after by one of their family members. The most common diseases were hypertension (59.0\%), diabetes mellitus (26.1\%), stroke (25.4\%), and Alzheimer's disease (23.9\%). The most common reason for applying to receive HBHC was neurologic diseases with 56.0\%, and old age with $29.8 \%$. Patients were found as fully dependent on others for bathing (97.0\%), climbing stairs (77.6\%), personal care (66.4\%), dressing and undressing (56.0\%), and for the toilet (56.7\%). According to the Barthel Index, 50.7\% of the group was fully dependent, and $29.9 \%$ of the group showed more advanced dependency. In those with Alzheimer's disease, the likelihood of being advanced or fully dependent was 9.9 times higher (95\% CI: 1.16-85.47; $\mathrm{p}=0.036)$.

Conclusion: The level of dependency in HBHC services is higher than many other specific groups. Alzheimer's disease was found to be the most important factor that increasing the need for HBHC. Therefore, more comprehensive service delivery with a multidisciplinary team approach is required.

Keywords: Healthcare at home; Dependency; Barthel Index

Abbreviations: HBHC: Home Based Health Care; ADL: Activity of Daily Living; BI: Barthel Index; NCD: NonCommunicable Diseases.

\section{Introduction}

Home-based health care (HBHC) service is the whole of the examination, diagnosis, treatment, medical care, follow-up and rehabilitation services given to individuals in their home and family environment, including social and psychological counseling services due to various diseases.

HBHC service is an important service model that provides continuity in health care and allows the person to receive services in a familiar environment. Nowadays, home health is an application that will be preferred for the provision of health and social services in many cases, especially in relation to old age, disability and chronic diseases [1-3]. The aim of 
home health services is to minimize the effects of disease and disability and to provide the maximum treatment and care. In this way, the quality of life will increase $[4,5]$.

As in the world, in Turkey, the elderly dependent population and the need of the HBHC service is increasing. While life expectancy at birth in Turkey has risen from 68.7 in 2003 to 78 in 2015 [6]. However, according to the "Turkey Disability Survey", the incidence of handicapped population is $12.3 \%$ and the incidence of disability due to chronic diseases in this population 9.7\% [7]. The dependency ratio of the elderly was $7 \%$ in 1990 and $12.2 \%$ in 2015 [8,9].

Healthcare needs are progressively increasing and hospital resources that will respond to this requirement are quite limited. On the other hand, an important part of the growing health need is those who need healthcare at home. In line with this service requirement, the organization of HBHC service should be regulated, and the patients who need health services should be well defined. Home- based health care services are provided by the teams established within the state hospitals affiliated with the Ministry of Health in Turkey and by the family physicians.

For the planning of health services which are provided to people at home; it is important to determine the cases of inadequacy of individuals and to reveal their sociodemographic characteristics correctly. The aim of this study was to determine the dependence levels and related factors of HBHC patients.

\section{Materials and Methods}

\section{Study Design}

Our research was a descriptive study. It was carried out in Bahçelievler, one of the most populous districts of Istanbul (district population 598.097). The population of the study consisted of 172 patients who were resident in the region and registered to the Ministry of Health because of the need for HBHC services between January $1^{\text {st }}-$ May $15^{\text {th }}, 2016$. It was completed with 134 patients who agreed to participate in the study. The patients were interviewed with the "HBHC service teams" at their homes and the questionnaire was answered by face to face interviews and responses were received from the patient or their relatives.
Within the scope of the research, a questionnaire form (sociodemographic characteristics, the need for HBHC, the chronic diseases and the use of multiple drugs (polypharmacy) were questioned) and the Barthel Index (to determine the level activity of daily living (ADL)) were applied $[10,11]$. Barthel Index (BI) consists of a total of 10 items evaluating such as feeding, bathing, personal care, dressing, defecation and urine control, toilet use, ability to transfer from bed to wheelchair, walking or wheelchairdependent and climbing stairs. The main objective of this scale is to determine the level of independence in ADL. The score varies between 0-100 and interpreted like 0-20 are fully dependent, 21-61 are highly dependent, 62-90 are moderately dependent, 91-99 dependent on a mild degree, 100 are fully independent.

\section{Statistical Analysis}

Descriptive statistics were reported as numbers (percentage) for categorical variables, the mean, standard deviation, minimum and maximum for continuous. Chi-square test was used for $2 \times 2$ contingency tables as appropriate for non-numerical data. The variables were investigated to determine if they are normally distributed. Two groups were compared with independent sample t-test for parametric variables.

For the multivariate analysis, the possible factors identified with univariate analyses were further entered the logistic regression analysis to determine independent predictors of dependence level. Hosmer Lemeshov goodness of fit statistics was used to assess model fit.

For statistical significance, $\mathrm{p}$ value $<0.05$ was accepted as significant in the $95 \%$ confidence interval. Statistical analyses were performed by using SPSS v 21.0. This study was approved by the Health Research Ethics Committee, Faculty of Medicine and Istanbul University.

\section{Results}

The mean age of the group was $77.5 \pm 14.7$ years. The descriptive characteristics of the participants are presented in Table 1 . The mean number of medications used daily was $5.0 \pm 3.1$ drugs $(0-15)$.

\begin{tabular}{|c|c|c|}
\hline Characteristics $(\mathbf{n = 1 3 4 )}$ & $\mathbf{n}$ & \% \\
\hline \multicolumn{2}{|c|}{ Gender } & 61 \\
\hline Female & 82 & 39 \\
\hline Male & 52 & \\
\hline Age & & \\
\hline
\end{tabular}




\begin{tabular}{|c|c|c|}
\hline $19-64$ & 18 & 13 \\
\hline $65-74$ & 16 & 12 \\
\hline $75-84$ & 59 & 44 \\
\hline$\geq 85$ & 41 & 31 \\
\hline \multicolumn{3}{|c|}{ Education } \\
\hline Illiterate & 58 & 43 \\
\hline Primary/secondary school & 67 & 50 \\
\hline High school and higher education & 9 & 6.7 \\
\hline \multicolumn{3}{|c|}{ Marital Status } \\
\hline Married & 51 & 38 \\
\hline Single/widow/divorced & 83 & 62 \\
\hline \multicolumn{3}{|c|}{ Family Income } \\
\hline$<430 \$$ & 7 & 5.2 \\
\hline $430-829 \$$ & 70 & 52 \\
\hline $830-1655 \$$ & 55 & 41 \\
\hline$>1655 \$$ & 2 & 1.5 \\
\hline \multicolumn{3}{|c|}{ Relationship of Caregiver } \\
\hline The son/ daughter & 83 & 62 \\
\hline Partner & 26 & 19 \\
\hline Caregiver & 17 & 13 \\
\hline Parents/ brothers & 7 & 5.2 \\
\hline No & 1 & 0.7 \\
\hline \multicolumn{3}{|c|}{ Number of People Living Together at Home } \\
\hline 1-3 people & 78 & 58 \\
\hline 4-5 people & 43 & 32 \\
\hline$\geq 6$ & 13 & 9.7 \\
\hline \multicolumn{3}{|c|}{ Smoking Status } \\
\hline Current smoker & 6 & 4.5 \\
\hline Non-smoker & 99 & 74 \\
\hline Former smoker & 29 & 22 \\
\hline Chronic disease (Yes) & 132 & 99 \\
\hline Polypharmacy (Yes) & 117 & 87 \\
\hline
\end{tabular}

Table 1: Frequency distribution of socio-demographic characteristics and medical history, of the studied population.

The distribution of chronic diseases of the participants was presented in Table 2 and $73.1 \%$ of them had more than one chronic disease.

\begin{tabular}{|c|c|c|}
\hline & $\mathbf{n}$ & $\mathbf{\%}$ \\
\hline Hypertension & 79 & 59 \\
\hline Diabetes mellitus & 35 & 26.1 \\
\hline Stroke & 34 & 25.4 \\
\hline
\end{tabular}




\begin{tabular}{|c|c|c|}
\hline Alzheimer's disease & 32 & 23.9 \\
\hline Cardiovascular disease (except hypertension) & 25 & 18.7 \\
\hline Osteoporosis, bone fracture & 20 & 14.9 \\
\hline Other musculoskeletal system diseases & 17 & 12.7 \\
\hline Neurological diseases (except Alzheimer's disease, dementia, stroke, Parkinson's) & 16 & 11.9 \\
\hline Respiratory system diseases & 16 & 11.9 \\
\hline Parkinson's disease & 11 & 8.2 \\
\hline Kidney disease & 9 & 6.7 \\
\hline Cancer & 7 & 5.2 \\
\hline Others* & 7 & 5.2 \\
\hline
\end{tabular}

Table 2: Chronic diseases of individuals receiving HBHC.

*Hyperlipidemia (2), hyperthyroidism (1), obesity (1), chronic hepatitis C disease (1), pleural effusion (1), chronic anemia (1).

The reasons of applying to HBHC services; $56.0 \%(\mathrm{n}=75)$ neurological disease, 29.8\% ( $\mathrm{n}=40)$ old age, 21.6\% $(\mathrm{n}=29)$ musculoskeletal disease, were determined as. In detail, as a reason for application; the proportion of those showing only "old age" is $17.9 \%(\mathrm{n}=24)$ and only "neurological diseases" is $41.0 \%(\mathrm{n}=55)$.

The most common complaints mentioned by individuals in the daily life were problems associated with moving, exercising $(71.6 \%(\mathrm{n}=96))$ pain $(41.8 \%(\mathrm{n}=56))$ fatigue $(26.9 \%(n=36))$.
In questioning $\mathrm{ADL} ; 35.1 \%(\mathrm{n}=47)$ of people couldn't eat without help, 97.0\% $(n=130)$ needed help for bath and $66.4 \%(n=89)$ needed help for personal care. $56.7 \%(n=76)$ of patients were completely dependent on toilet needs, only $14.2 \%(n=19)$ could do independently. While $64.9 \%$ of the patients could not walk, $77.6 \%$ of them could not climb stairs.

BI total score of the participants was $31.3 \pm 30.1$ and the median value was $20(0-100)$, and $50.7 \%(n=68)$ of them were fully dependent, $29.9 \%(n=40)$ were in the highly dependent Table 3.

\begin{tabular}{|c|c|c|c|c|c|}
\hline & \multicolumn{2}{|c|}{ Fully/highly dependent } & \multicolumn{2}{|c|}{ Moderately/mildly dependent } & \multirow{2}{*}{$\mathbf{p}$} \\
\hline & $\mathbf{n}$ & $\%$ & $\mathbf{n}$ & $\%$ & \\
\hline \multicolumn{6}{|l|}{ Gender } \\
\hline Female & 68 & 82.9 & 14 & 17.1 & \multirow{2}{*}{0.392} \\
\hline Male & 40 & 76.9 & 12 & 23.1 & \\
\hline \multicolumn{6}{|c|}{ Education } \\
\hline Illiterate & 48 & 82.8 & 10 & 17.2 & \multirow{3}{*}{0.854} \\
\hline Primary/secondary school & 53 & 79.1 & 14 & 20.9 & \\
\hline High school and higher education & 7 & 77.8 & 2 & 22.2 & \\
\hline \multicolumn{6}{|l|}{ Marital Status } \\
\hline Married & 40 & 78.4 & 11 & 21.6 & \multirow{2}{*}{0.619} \\
\hline Single/widow/divorced & 68 & 81.9 & 15 & 18.1 & \\
\hline Age* & \multicolumn{2}{|c|}{$76.7 \pm 14.7(19-101)$} & \multicolumn{2}{|c|}{$82.5 \pm 11.4(53-103)$} & 0.041 \\
\hline \multicolumn{6}{|c|}{ Chronic diseases } \\
\hline Hypertension & 58 & 73.4 & 21 & 26.6 & 0.012 \\
\hline Cardiovascular disease (except hypertension) & 20 & 80 & 5 & 20 & 0.933 \\
\hline Diabetes Mellitus & 28 & 80 & 7 & 20 & 0.917 \\
\hline Alzheimer's Disease & 31 & 96.9 & 1 & 3.1 & 0.008 \\
\hline Stroke & 30 & 88.2 & 4 & 11.8 & 0.192 \\
\hline
\end{tabular}




\begin{tabular}{|c|c|c|c|c|c|}
\hline Polypharmacy (Yes) & 93 & 79.5 & 24 & 20.5 & 0.752 \\
\hline \multicolumn{6}{|c|}{ Reason for Contacting HBHC Services } \\
\hline Neurological diseases & 67 & 89.3 & 8 & 10.7 & 0.004 \\
\hline Musculoskeletal system diseases & 24 & 82.8 & 5 & 17.2 & 0.739 \\
\hline Old age & 26 & 65 & 14 & 35 & 0.003 \\
\hline
\end{tabular}

Table 3: Comparison of the dependency groups with independent factors $(n=134)$.

*Mean \pm standard deviation (minimum-maximum).

The mean age of the individuals in the fully/highly dependent group was lower $(\mathrm{p}=0.041)$. It was also found that patients with Alzheimer's disease and those who received service because of neurological disease were more in the fully/highly dependent group $(\mathrm{p}<0,05)$ (Table 3 ).
Logistic regression analysis was performed to determine the independent predictor. Among those with Alzheimer's disease, the probability of "highly or fully dependent" was 9.9 times more (\% 95 CI 1.16-85.47 p = 0.036) than those who were not (Table 4).

\begin{tabular}{|c|c|c|c|c|}
\hline & Odds Ratio & 95\% Confidence & Interval & $\mathbf{p}$ \\
\hline Age (year) & 0.98 & 0.94 & 1.03 & 0.4 \\
\hline Hypertension & 0.35 & 0.11 & 1.08 & 0.1 \\
\hline Alzheimer's disease & 9.94 & 1.16 & 85.47 & 0 \\
\hline Elderly (Reason for Contacting HBHC Services) & 0.38 & 0.13 & 1.11 & 0.1 \\
\hline $\begin{array}{c}\text { Neurological Diseases (Reason for Contacting HBHC } \\
\text { Services) }\end{array}$ & 1.44 & 0.47 & 4.41 & 0.5 \\
\hline
\end{tabular}

Table 4: Logistic regression analysis of independent variables related to BI dependency groups in individuals receiving HBHC.

\section{Discussion}

Dependence levels and related factors were evaluated in patients receiving HBHC. In our study, prevalence of hypertension was $59 \%$, diabetes mellitus $26.1 \%$, stroke $25.4 \%$, Alzheimer's disease $23.9 \%$. Similar studies have shown that, hypertension was between $46-48 \%$, diabetes mellitus $15.7 \%$, stroke $39.8 \%$, Alzheimer $12.0 \%$ [12-14]. In a meta-analysis study, the prevalence of Alzheimer's disease was $8.4 \%$ in all age groups and $26.8 \%$ in 80 years and older [15]. In a study conducted with dementia patients also found similar increase in elderly [16]. Although the rates were similar to the results of our study, the rate of Alzheimer's disease in our group was high; it may be due to the increase in the diagnosis of Alzheimer's disease and the fact that Alzheimer's patients more resort to HBHC.

According to the Turkish Health Survey 2012 report, hypertension $(11.3 \%)$ and diabetes mellitus (6.5\%) are among the 5 most common diseases diagnosed by physicians [17]. The prevalence of hypertension in Turkey is $30.3 \%$, and 80 years and older is known to rise to $76.3 \%$ [18]. Similarly, the prevalence of diabetes mellitus is $16.5 \%$, which increases to $35 \%$ over the age of 80 [19].

Nowadays, non-communicable diseases (NCD) are one of the leading causes of mortality and morbidity. It is known that about $86 \%$ of the deaths in Turkey are due to NCD and that cardiovascular diseases are the first place with $47 \%$ [20]. The prevalence of these diseases increases with age. The increase in life expectancy at birth and effective treatments in the control of chronic diseases is very effective in increasing the NCD prevalence. HBHC patients are a group of patients with an increased incidence of chronic diseases and multiple illnesses. Chronic diseases such as hypertension and diabetes, which are not controlled, may complicate existing problems in people (delay in wound healing etc.), at the same time may also cause secondary problems. Therefore, control of chronic diseases in the HBHC group is an important step in preventing especially the complications and decreasing the related health expenditures [21].

The reasons of applying to HBHC services; $56.0 \%$ neurological disease, $29.8 \%$ old age, was determined as. Also, in the related literature, neurological diseases (\%19.350.3 ) have been identified as the most common reason for receiving HBHC [22-24].

In this study patients' dependency rate in ADL were; $97.0 \%$ for bathing, $66.4 \%$ for personal care, $56.7 \%$ for toilet needs, $64.9 \%$ for walking, $35.1 \%$ for eating.

Inability to walk ratio in the urban centers in Turkey was 
$3.1 \%$, this rate rises to $36.5 \%$ over 75 years and older. When evaluating ADL in Turkey 75 years and older "difficulty/not being able to self" expression was used for bathing 31\%, for dressing $25 \%$, for toilet use $24 \%$, for eating without help $17 \%$ [17]. In literature evaluating the ADL of individuals receiving HBHC services, high rates of dependency were determined like in our study and "not possible to do / fully dependent" expression was used $30.6-85.3 \%$ for bathing, $17.6-81.9 \%$ for dressing up, $28.2-41.7 \%$ for toilet use, $9.3-14.1 \%$ for eating $[3,12,22,23]$.

According to the BI $80.6 \%$ of patients "highly or fully dependent" (50.7\% were fully dependent) have been detected. In the group 75 years and older who were living in urban centers Turkey, the rate of severely restricted ADL within the past 6 months was $77.3 \%$ [17]. In the studies evaluating the ADL in patients receiving $\mathrm{HBHC}$, fully dependency was found in $27.8-44.2 \%[12,14]$.

In a study conducted with patients who had stroke by Gorgulu, et al. 65\% of the patients were found to be highly/ fully dependent [25]. It is evident that those with stroke have aggravated the level of dependence according to the normal population. In our study, other neurological diseases present may have altered this effect in patients receiving HBHC.

It was determined that those who received home health care services due to neurological diseases were in fully/ highly dependent group mostly. On the other hand, it was found that people who received home health care because of old age were moderately/ mildly dependent. Although it is known that dependency increases with old age, the reason why the result of our univariate analysis is completely opposite; may be that elderly people generally have been included in the home health care for sociocultural reasons [26]. As a matter of fact, when multivariate analyzes were performed, it was found that Alzheimer's Disease may increase the risk of fully/highly dependent up to 10 times in individuals receiving home health care.

\section{Conclusion}

As in our study group, people who receive HBHC are usually in elderly group and have many disease burdens. The population projections show that the population is getting older and the life expectancy at birth is increasing. With the rapidly increasing elderly population, the increase in chronic diseases and disability rates increase the need for care. In this study, Alzheimer's disease was found to be the most important factor that increasing the need for HBHC. Studies in the literature have also shown that the increased prevalence of Alzheimer's each year.

This shows that the need for HBHC services, which provides effective protection and treatment at low cost from health care services, will progressively increase. Therefore, it should be kept in mind that the HBHC should be presented in a multidisciplinary approach and that the caregiver should be specially trained and equipped.

\section{Funding}

No financial support was received for this study.

\section{Conflict of Interest}

The authors declare no conflict of interest.

\section{References}

1. Tarricone R, Tsouros AD (2008) Home care in Europe: the solid facts. 2008: WHO Regional Office Europe, pp: 1-35.

2. Tanli S, Utku T (2008) Organization and Ethical Issues in Home Care. Turkish Journal of Intensive Care Medicine 6(4): 58-63.

3. Taşdelen P, Ateş M (2012) The Needs of Home Care Patients and the Burdens of their Caregivers. Journal of Education and Research in Nursing 9(3): 22-29.

4. Tanli S (1996) Customizing the Home Care Services: A Business Administration Plan Proposal, in Institute of Social Sciences, Istanbul University.

5. Çoban M, Esatoğlu AE (2004) Home Care: An Overview. Turkiye Klinikleri Journal of Medical Ethics-Law and History 12(2): 109-120.

6. (2016) Life Tables, 2013-2015 Turkish Statistical Institute.

7. (2004) Turkey Disability Survey 2002. State Institute of Statistics Prime Ministry Republic of Turkey.

8. (2015) Elderly with Statistics 2015, in PreHaber Bultenleri, Turkish Statistical Institute.

9. Bilir N (2004) Aging Society. Hacettepe University Faculty of Medicine Department of Public Health.

10. Viktil KK, Blix HS, Moger TA, Reikvam A (2007) Polypharmacy as commonly defined is an indicator of limited value in the assessment of drug-related problems. Br J Clin Pharmacol 63(2): 187-195.

11. Küçükdeveci AA, Yavuzer G, Tennant A, Süldür N, Sonel B, et al. (2000) Adaptation of the modified Barthel Index for use in physical medicine and rehabilitation in Turkey. Scandinavian journal of rehabilitation medicine 32(2): 
87-92.

12. Çatak B (2012) Profile of Elderly Patients Who Use Health Services in their Homes and in-Home Care. Turkish Journal of Public Health 10(1): 13.

13. Karaman D, Kara D, Atar N (2015) Care Needs And Disease States Of Individuals, Who Home Health Care Services Are Provided Evaluating: Example of Zonguldak Province. Journal of Health Sciences.

14. Ayraler A, Akan H, Hayran O (2013) Nutritional Status of Elderlies Admitted to Home Health Care Service. Turkish Journal of Family Practice 17(3): 106-112.

15. Li K, Wei S, Liu Z, Hu L, Lin J, et al. (2018) The Prevalence of Alzheimer's Disease in China: A Systematic Review and Meta-analysis. Iranian Journal of Public Health 47(11): 1615-1626.

16. Seetlani NK, Kumar N, Imran K, Ali A, Shams N, et al. (2016) Alzheimer and vascular dementia in the elderly patients. Pakistan journal of medical sciences 32(5): 1286-1290.

17. (2013) Health Survey in Turkey 2012. Turkish Statistical Institute.

18. Sengul S, Akpolat T, Erdem Y, Derici U, Arici M, et al. (2016) Changes in hypertension prevalence, awareness, treatment, and control rates in Turkey from 2003 to 2012. J Hypertens 34(6): 1208-1217.

19. Satman I, Omer B, Tutuncu Y, Kalaca S, Gedik S, et al.
(2013) Twelve-year trends in the prevalence and risk factors of diabetes and prediabetes in Turkish adults. Eur J Epidemiol 28(2): 169-180.

20. Riley L, Cowan M (2014) Noncommunicable diseases country profiles 2014. Geneva: World Health Organization.

21. (2015) Turkey diabetes program 2015-2020. Republic of Turkey Ministry of Health.

22. Enginyurt Ö, Öngel K (2012) Sociodemographic Characteristics and Medical Conditions of Patients Under Homecare Service. Smyrna Medical Journal 3: 45-48.

23. Subaşı N, Öztek Z (2006) An unmet need in Turkey: Home care services. TAF Preventive Medicine Bulletin. 5(1): 19-31.

24. Yörük S, Çalışkan T, Gündoğdu H (2012) Determining The Reasons for Taking Care of and The Services Provided for The Elderly Individuals age 65 and Over who take care from The Balıkesir State Hospital Home Care Unit. Balıkesir Saglik Bilimleri Dergisi 1(1): 12-15.

25. Gorgulu U, Polat U, Kahraman B, Ozen S, Arslanet E (2016) Factors affecting the burden on caregivers of stroke survivors in Turkey. Medical Science and Discovery 3(4): 159-165.

26. Yiğitbaş Ç Deveci SE (2016) Disability in the Elderly in Terms of Public Health. Bakırköy Medical Journal 12(2): 57-63.

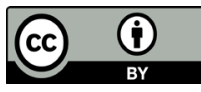

Ören MM and Önal AE. Dependency Levels and Related Factors of Individuals Receiving Home Based Health Care in Turkey. Nurs Health Care Int J 2020, 4(2): 000217. 